\title{
Defining the role of elastic modelling in underground mine design
}

\author{
BJ Barsanti Newmont Asia Pacific, Australia \\ FRP Basson Newmont Asia Pacific, Australia
}

\begin{abstract}
Finding the most appropriate way to use elastic modelling results in a production environment is sometimes challenging. Many design criteria are available, but have to be used within the context of the failure mechanism and the correct field stress. Some design criteria require the explicit modelling of nearby excavations, but others do not. This distinction is important, but often overlooked in numerical analysis.

Establishing correlations between modelling results and observations (or measurements) are crucial to confidently use stress results for predictions, but seldom achieved. Many times correlations do exist, but not exposed due to ineffective observation techniques and a poorly selected design criterion.

The final challenge in the numerical modelling process is to present the results and interpreted outcomes to mine management and planning engineers in a clear and concise manner. An effective communication technique is important but often overlooked, which can impact hugely on the understanding of the given advice.

This paper shares the authors' learnings on the above after being confronted with these questions many times during their careers. They aim to transfer their combined experience and selected techniques with case studies.
\end{abstract}

\section{Introduction}

In recent decades, geotechnical engineers have been forced to consider and develop a rigorous approach to problem solving through conscious (explicit) model building. Conscious model building is a process of developing a model with a well-defined purpose recognised by the model builder.

Numerical models attempt to simulate the way a rock mass responds to mining with mathematics. The model consists of loading conditions (overburden and tectonic forces), geometry of excavations, geology, and modelling assumptions. In hard brittle rocks, most of the rock mass will respond elastically with yielding zones confined to the immediate vicinity of excavations and pillars. In these rock masses, elastic modelling is sufficient for many design cases, and the focus of this discussion.

Finding the most appropriate way to use elastic modelling results in a production mining environment could be challenging. Many design criteria are available, but have to be used within the context of the failure mechanism and the correct field stress. Some design criteria require the explicit modelling of nearby excavations, but others do not. This distinction is important, but often overlooked in numerical analysis.

In the context of this discussion, a design criterion can be any combination of parameters that relates in some way to an observed outcome. Well-known design criteria are the major principal stress $\left(\sigma_{1}\right)$, minor principal stress $\left(\sigma_{3}\right)$ and rock wall condition factor (RCF). Failure criteria refer to the formally accepted criteria, such as the Mohr-Coulomb and Hoek-Brown failure criteria and could occasionally function as design criteria.

This paper shares the authors' learnings on best practices when using elastic numerical modelling in a production environment, after being confronted with these questions many times during their careers. The aim of the paper is to transfer our combined experience and selected techniques with case studies. 


\section{$2 \quad$ Far-field versus near-field design criteria}

Much of the design process in rock engineering is qualitative due to the many uncertainties facing geotechnical engineers. It is necessary to employ relevant design criteria in order to quantify the comparison of various mine designs. Mine design criteria for excavation stability could be based on two different stress field approaches; the first is where the remote field stresses are considered (far-field stress), and the second where the near-boundary stresses are considered (near-field stress).

Figure 1 shows an example where the stress impact from stoping on tunnel conditions is assessed. This could be done with a far-field or near-field approach, and the difference discussed in the two sub-sections following Figure 1.
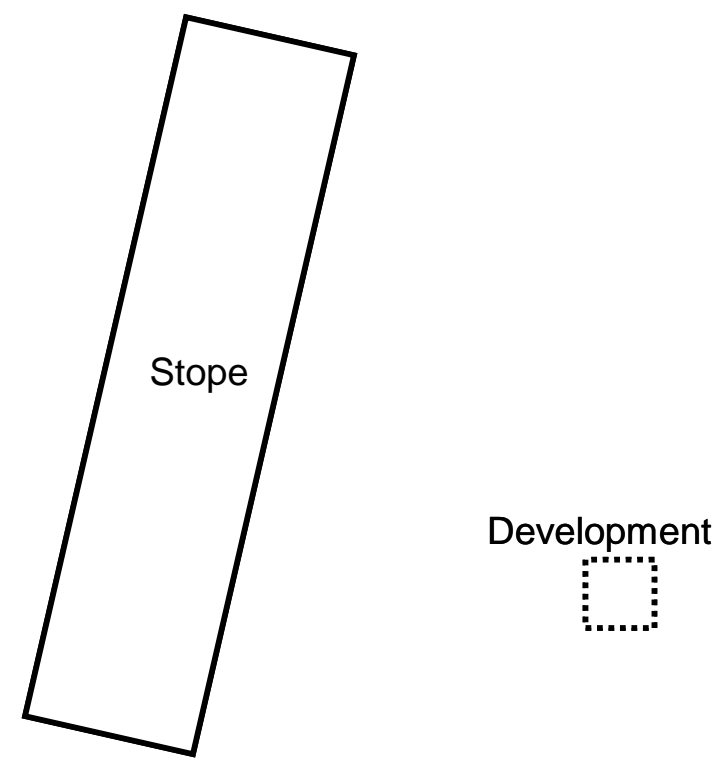

Figure 1 Section view of a stope and development to illustrate different design approaches

\section{$2.1 \quad$ Far-field stress}

A simple approach would be to assess the stress condition at the proposed tunnel position before explicit extraction of the tunnel. The anticipated conditions are thus based on the field stresses at the excavation position before extraction (i.e. the excavation is not explicitly included within the model). The advantage of this approach is that it is quick and can allow multiple development position to be evaluated from a single model. It is also possible to contour criterion values to determine the best location for the tunnel.

\subsection{Near-field stress}

A more detailed approach would be to explicitly excavate the tunnel in the model and then estimate tunnel conditions from stresses in the direct vicinity of the excavation. This is the most common way of using numerical models. Determining near-boundary stresses requires substantially more effort; as each potential development position has to be explicitly modelled and the results compared to obtain the best location.

\subsection{Kirsch equations}

Analytical solutions apply to simple geometries only, for example a circular tunnel in an otherwise intact rock mass. A well-known analytical approach is the use of Kirsch equations that describe stress concentrations around a circular opening. A simplified version of the more general case found in textbooks is shown in Figure 2. This equation calculates the stresses at a circular opening perimeter (near-field stress) from the far-field stresses. The tangential stresses at the two points $\sigma_{A}$ and $\sigma_{B}$ shown in Figure 2 are respectively given by Equations 1 and 2 . 


$$
\begin{gathered}
\sigma_{A}=3 . \sigma_{1}-\sigma_{3} \\
\sigma_{B}=3 . \sigma_{3}-\sigma_{1}
\end{gathered}
$$

These formulas will again be referenced when discussing the far-field design criteria such as RCF.

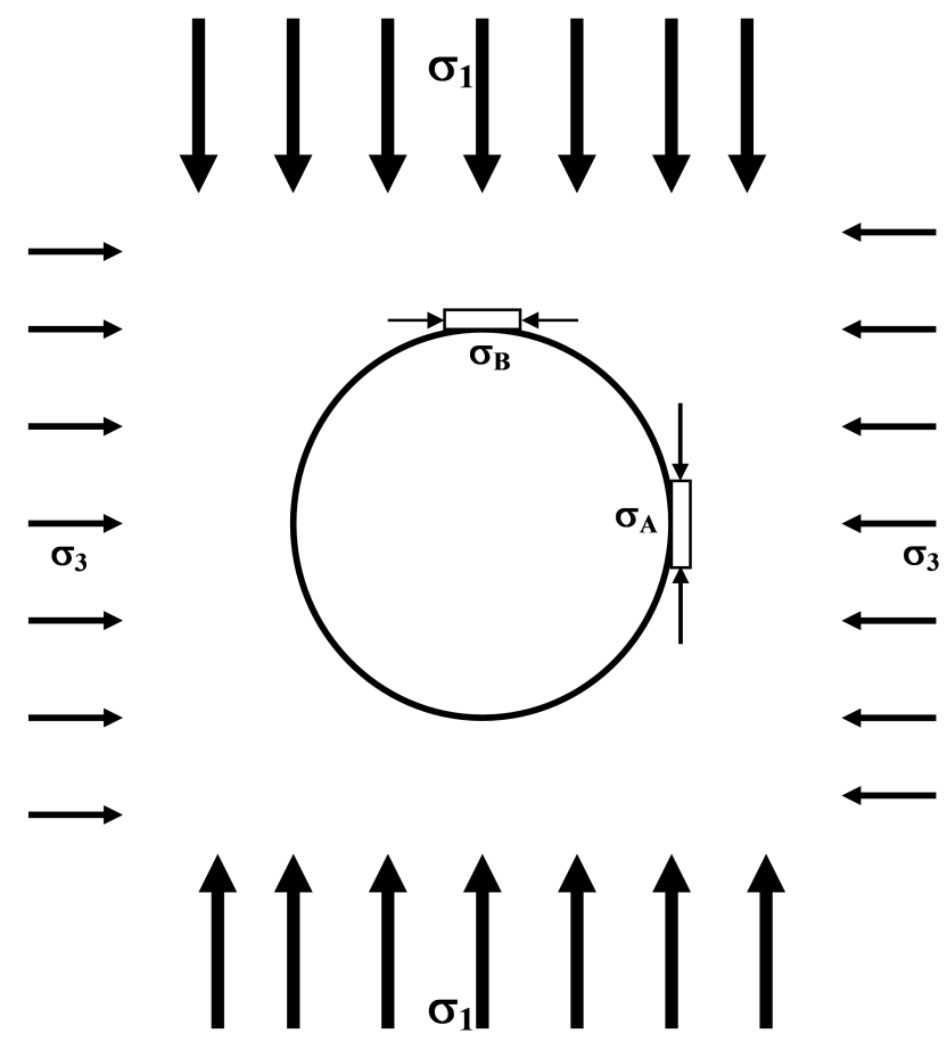

Figure 2 Analytical (closed form) stress equations around circular openings

\section{Useful design criteria}

For stress modelling to be useful, a first requirement is that the observed rock behaviour must correspond to a stress condition or change. Without such a relationship, predictive stress modelling with a reasonable level of confidence is not possible.

An assumption with elastic modelling is that increased overstressing causes increased damage to the rock mass. The relationship between over-stressing and damage is not always known, and Figure 3 aims to show potential relationships that could occur. The amount of damage that occurs is generally a function of the system stiffness that could drive the failure, as it controls how much deformation could occur when the peak strength is exceeded. Inspection of the elastic stresses alone will not give any indication of the expected deformation, as the modelled stresses can only indicate non-failure, failure, and the amount of overstressing. This limitation is partially eliminated in back-analysis, where the system stiffness of the previously assessed case studies is typically similar to future prediction sites, and thus accounted for in the results. 

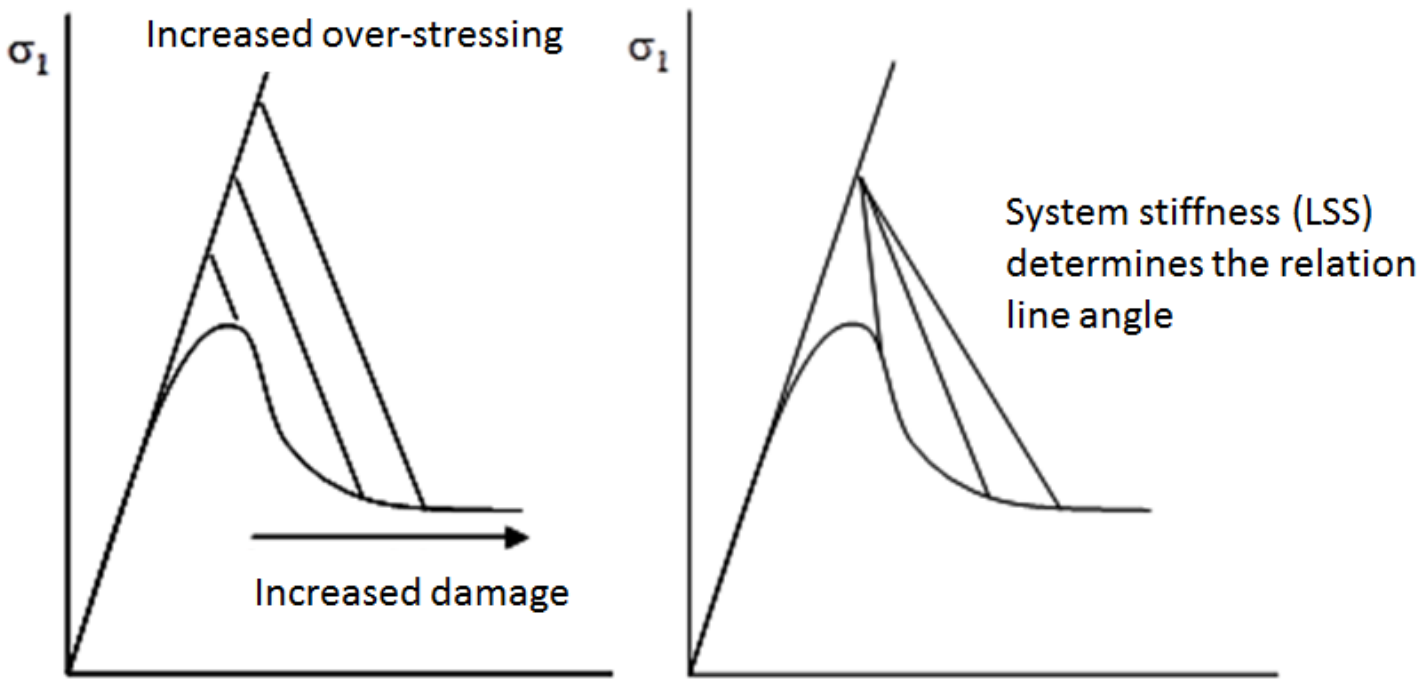

Figure 3 The relationship between over-stressing and observed damage (Wiles 2004)

The most commonly used mine design criteria are discussed in the following sections.

\subsection{Major principal stresses $\left(\sigma_{1}\right)$}

Major principal stress-values $\left(\sigma_{1}\right)$ could be sufficient to determine expected conditions in excavations as a first estimate. Although minor principal stress $\left(\sigma_{3}\right)$ is not taken into account, areas where more detail analyses are required could be identified with this criterion.

For example, the following empirical rules apply to the field stresses of brittle quartzite in South African Gold Mines (Ozbay 1995):

- $1 / 3$ UCS intact start of rock mass damage.

- $1 / 2$ UCS $_{\text {intact }}$ substantial damage.

- $2 / 3$ UCS intact uncontrollable damage.

The major principal stress is largely used as a far-field criterion, but can also be used as a near-field design criterion.

\subsection{Rock wall condition factor}

A refinement of using only $\sigma_{1}$ is to incorporate $\sigma_{3}$ as done in the RCF. This method combines an analytical (closed form) solution with numerical modelling for a design criterion. Effectively, this approximates a near-boundary stress condition.

The maximum stress concentration at the skin of a circular opening can be calculated by the Kirsch equation and combining with inverse Factor of Safety (FS), the RCF criterion can be deduced:

$$
R C F=\frac{\text { Stress }_{\text {rockmass }}}{\text { Strength }_{\text {rockmass }}}=\frac{3 \cdot \sigma_{1}-\sigma_{3}}{F \cdot \sigma_{c}}
$$

where:

$F \quad=$ a downgrading factor from the intact rock to the rock mass strength.

$R C F=$ a far-field design criterion only, as the stress change from the development is accounted by the Kirsch equation. 


\subsection{Extension strain $\left(\varepsilon_{3}\right)$}

Extension strain is one of very few criteria that incorporate all three principal stress components. It was originally called the 'limiting tensile strain criterion', and fractures occur when the tensile strain exceeds a limiting value. For a material with linear deformation behaviour, fractures will form in the direction of the Minor Principal Stress, and the strain in this direction defined by Equation 4 (Stacey 1981).

$$
\varepsilon_{3}=\frac{1}{E}\left[\sigma_{3}-v\left(\sigma_{1}+\sigma_{2}\right)\right]
$$

$$
\begin{array}{ll}
\sigma_{1}, \sigma_{2} \text { and } \sigma_{3} & =\text { principal stresses. } \\
E & =\text { Young's modulus of intact rock. } \\
V & =\text { Poisson's ratio. }
\end{array}
$$

Equation 4 illustrates that extension fractures could form when all three principal stresses are compressive, and thus in planes across which the net macro stress is compressive. When using the formula in Map3D (Wiles 2015), write the formula as in Equation 5 to get results in micro-strain $(\mu \varepsilon)$ units (Louchnikov 2011).

$$
\varepsilon_{3}=-1 / E^{*}\left(s 3-v^{*}(s 1+s 2)\right) * 10^{\wedge} 6
$$

$E$ and $v$ should be typed as real numbers, with $E$ in $\mathrm{MPa}$. Extensions are negative strains and the reason for the negative sign at the front of the equation. Critical extension strains for the onset of fracturing have to be back-analysed for each geotechnical domain at a site, but typical values range from 100 to $300 \mu \varepsilon$.

Extension strain is a near-field design criterion only, as it estimates the progress of fractures from the excavation surface.

\subsection{Design criteria derived from $\sigma_{1}-\sigma_{3}$ charts}

The general methodology described below is applicable to a wide range of problems, and largely used as a near-field design criterion.

\subsubsection{Step 1: underground observations}

Inspect existing excavations (or instrumentation readings) and decide on relevant condition categories, for example a site-specific stress damage scale similar to Table 1. Other example categories are shown in Table 2.

Table 2 Example applications for the design criteria derived from $\sigma_{1}-\sigma_{3}$ charts

\begin{tabular}{cccc}
\hline $\begin{array}{c}\text { Example } \\
\text { applications }\end{array}$ & Category A & Category B & Category C \\
\hline $\begin{array}{c}\text { Support } \\
\text { requirements }\end{array}$ & Friction bolts suffice & $\begin{array}{c}\text { Mesh to floor and } \\
\text { additional friction bolts }\end{array}$ & $\begin{array}{c}\text { Grouted bolts and } \\
\text { occasional shotcrete }\end{array}$ \\
\hline Ground conditions & $\begin{array}{c}\text { No observed stress } \\
\text { damage }\end{array}$ & $\begin{array}{c}\text { Stress damage visible, but } \\
\text { normal support suffice }\end{array}$ & $\begin{array}{c}\text { Stress damage extensive, } \\
\text { additional support } \\
\text { required }\end{array}$ \\
\hline Drilling difficulty & Little drilling difficulty & $\begin{array}{c}\text { Moderate drilling difficulty } \\
- \text { occasional hole closure }\end{array}$ & $\begin{array}{c}\text { Severe drilling difficulty } \\
- \text { frequent hole closure }\end{array}$ \\
\hline $\begin{array}{c}\text { Rehabilitation } \\
\text { requirements }\end{array}$ & $\begin{array}{c}\text { Medium } \\
\text { Low }\end{array}$ & $\begin{array}{c}\text { High } \\
\text { (<5\% of development })\end{array}$ & (>30\% of drive $)$ \\
\hline
\end{tabular}


The number of categories and the specifics of the observation will differ between mine sites and even different geotechnical areas on the same site.

\subsubsection{Step 2: model observed failure}

Create the relevant voids in a numerical model, it is sensible to only incorporate the development voids that will influence the areas under consideration to limit model run times. The stress conditions are required at the time of rock mass failure, so it is critical to replicate (as close as practicable) the point in the stoping sequence that resulted in the observed conditions in Step 1. Choose appropriate model parameters suitable to the resolution of the problem being investigated; for example model parameter AG in Map3D (Wiles 2015) should be equal to the smallest dimension of interest and AL equal to twice the smallest pillar or stope width. Finally, run the model analysis.

The authors recommend that the model parameters be fixed for a specific failure criterion. All back-analysis simulations, as well as future assessments which use that particular failure criterion, must to be done with the same set of model parameters. This is required to limit the introduction of artificial effects from different grid resolutions and analysis control parameters.

\subsubsection{Step 3: tabulate results and obtain a design criteria}

The stress conditions applicable to each observed area are tabulated with the category assigned to each observation. Plot the tabulated results on a $\sigma_{1}$ versus $\sigma_{3}$ graph, using different colours (or symbols) to indicate categories as shown in Figure 4.

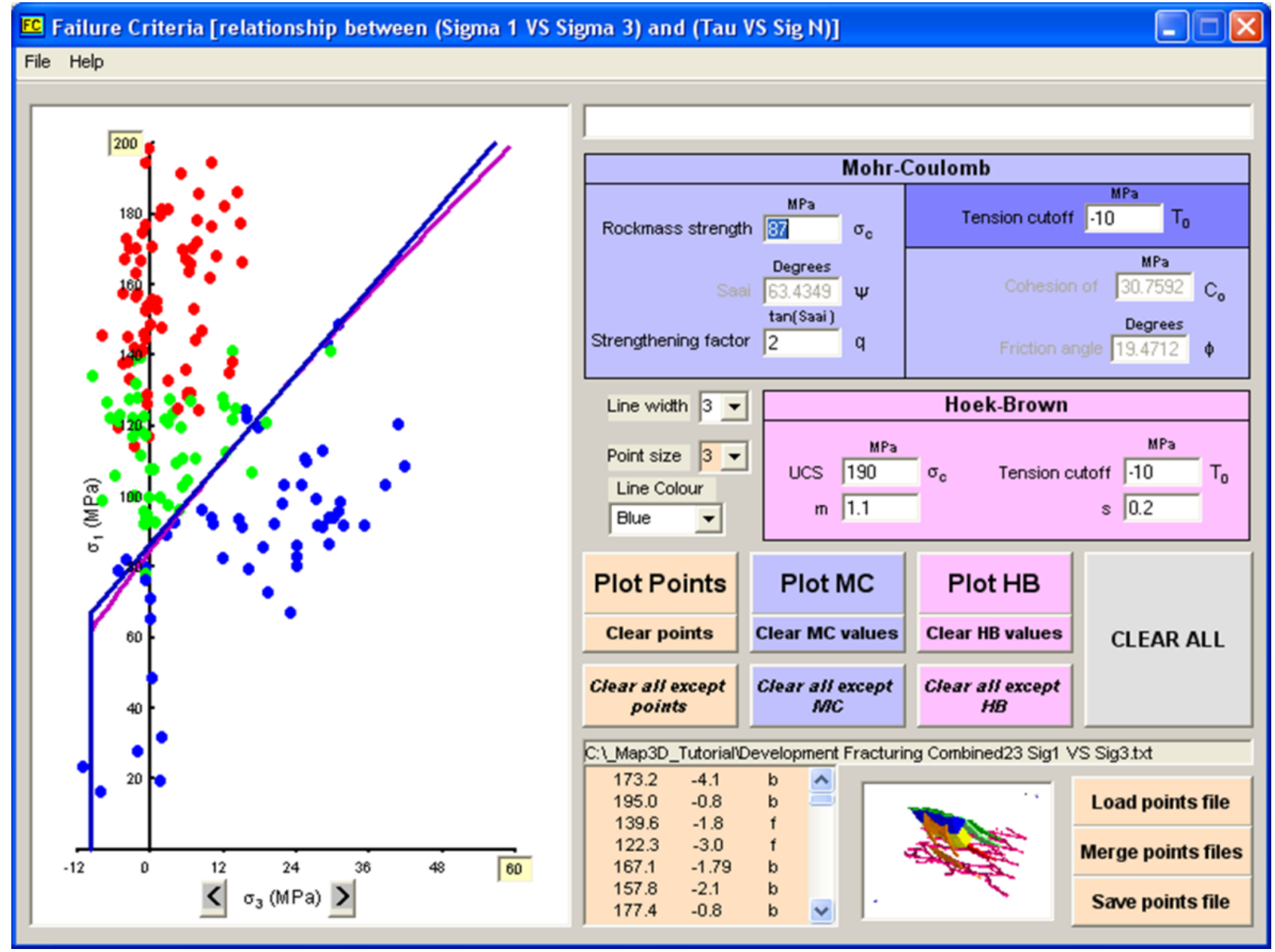

Figure 4 Two design criteria from tabulated results shown in Failure Criteria (BasRock Software for Geotechs 2014) 
Although both the Mohr-Coulomb and Hoek-Brown design criteria are shown in Figure 4, the straight-line Mohr-Coulomb criterion is normally sufficient to define different categories of observation. The straight-line equation is also easier to assess in the final stage of the development.

The Mohr-Coulomb result from the first graph in Figure 4 is $\sigma_{1}=2.0 \sigma_{3}+87$. The driving failure is $\sigma_{1}$ and the resistance to failure $2.0 \sigma_{3}+87$. Using the definition of $\mathrm{FS}$, the result can be expressed as Equation 3 , or the inverse as Equation 4.

$$
\begin{gathered}
\text { FOS }=\frac{\text { Capacity }}{\text { Demand }}=\frac{\text { Strengt }_{\text {rockmass }}}{\text { Stress }_{\text {rockmass }}}=\frac{2.0 \sigma_{3}+87}{\sigma_{1}} \\
\text { FOS }^{-1}=\frac{\text { Demand }}{\text { Capacity }}=\frac{\text { Stress }_{\text {rockmass }}}{\text { Strengt }_{\text {rockmass }}}=\frac{\sigma_{1}}{2.0 \sigma_{3}+87}
\end{gathered}
$$

Simply, when the FOS ${ }^{-1}$ exceeds a value of 1 additional ground support or rehabilitation will be required and conversely a value of less than 1 the standard ground support will suffice.

\subsubsection{Step 4: test observations against the design criterion}

The Terzaghi observational approach to design is based on the back-analysis of known events, and a continuous loop between design, mine and monitor. Thus, start with an initial design, start the mining process, monitor the rock mass response, use the results to redesign, and repeat the process. In the same way, the design criteria should be applied, the accuracy monitored, and the design criteria adjusted if required.

When the design criterion is proven useful, it could be used in predictive analysis.

\section{$4 \quad$ Correlation and calibration}

Calibration cannot be achieved with elastic modelling, but correlations can sometimes be made between observations and stress results, when the observed damage is related to high stress conditions. As correlation and calibration are sometimes used interchangeably, a discussion follows that differentiates between these two concepts.

Correlation is the relationship between two variables, and includes the extent to which one variable is influenced by a change in another. Correlation is determined by qualitative measures, such as the relationship between observed ground conditions and the stresses from numerical modelling as described in this paper.

Calibration is the establishment of a numerical relationship between variables. In numerical modelling that would mean to choose attribute values and parameters that enable a model to accurately represent the real-world situation and a quantitative measure. Calibration falls outside the scope of this discussion.

AMC compiled a stress damage scale with photographs that could be used to recognise stress damage in typical Australian mines (see Figure 5). The AMC-scale enables distinction between levels of stress-induced damage on a mine and a good tool to establish a correlation between observations and modelled stress values.

\section{$5 \quad$ Examples of design criteria correlations with observations}

The purpose of the examples in this section is to demonstrate some practical applications of design criteria as part of mine design. A few visualisation techniques that the authors found useful in particular scenarios are also demonstrated. 


\subsection{Example 1: far-field back-analysis of existing excavations}

This example is not about displaying numerical modelling results, but how underground observations could be correlated to the far-field stress. Two different design criteria ( $\sigma_{1}$ and RCF) were evaluated to find the criterion that provides the best correlation with observed conditions.

The process followed was very simple:

- Inspect the development once established, and rate the stress condition of the tunnel similar to shown in Figure 5. Divide the tunnels into three categories 'moderate stress', 'high stress' and 'very high stress'.

- Determine the far-field stress at the development locations from the stoping voids in a boundary element package.

- Plot the outcomes of the different design criteria for each excavation as shown in Figures 6 and 7. 


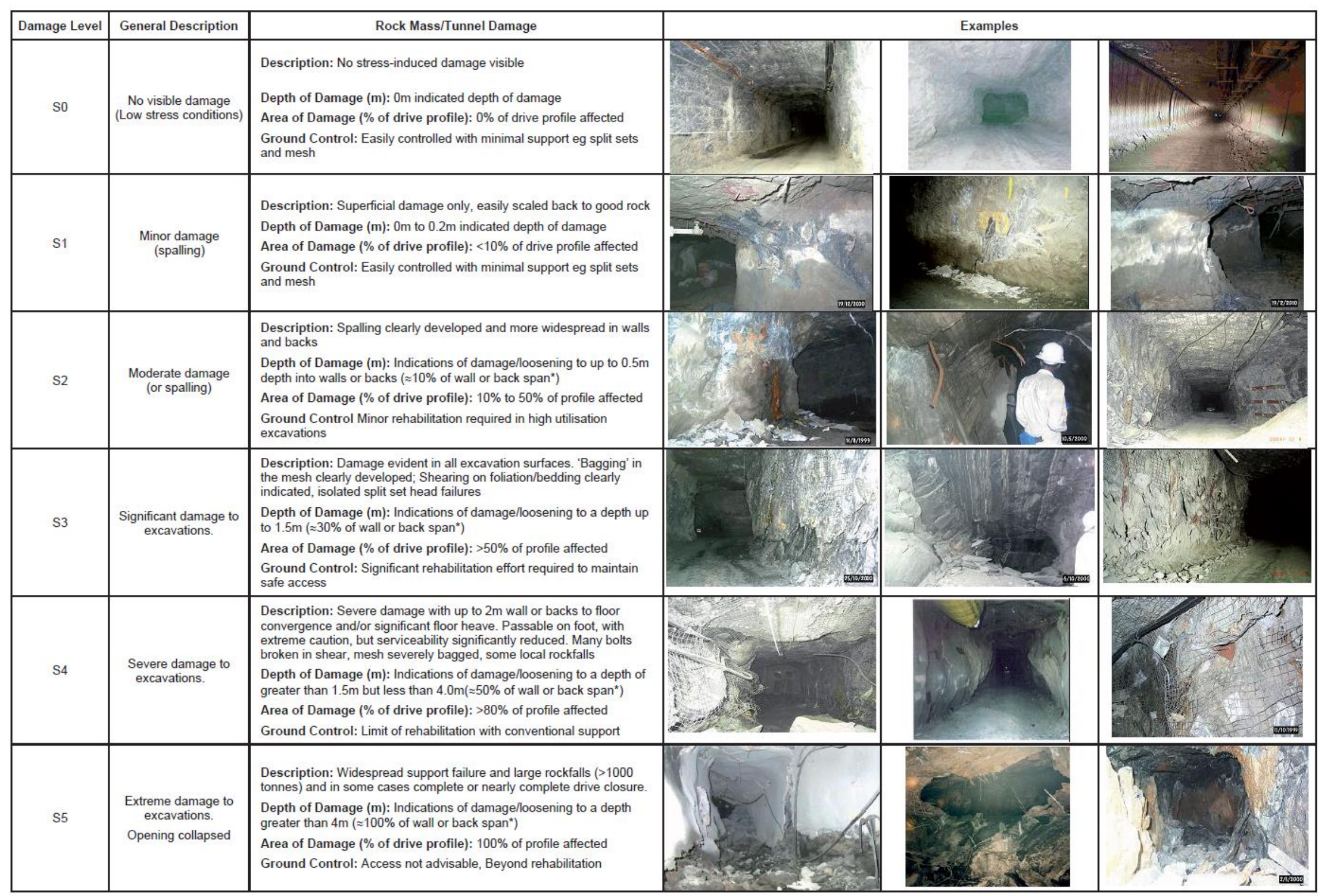

Figure 5

AMC stress-driven damage scale (Sandy 2010) 


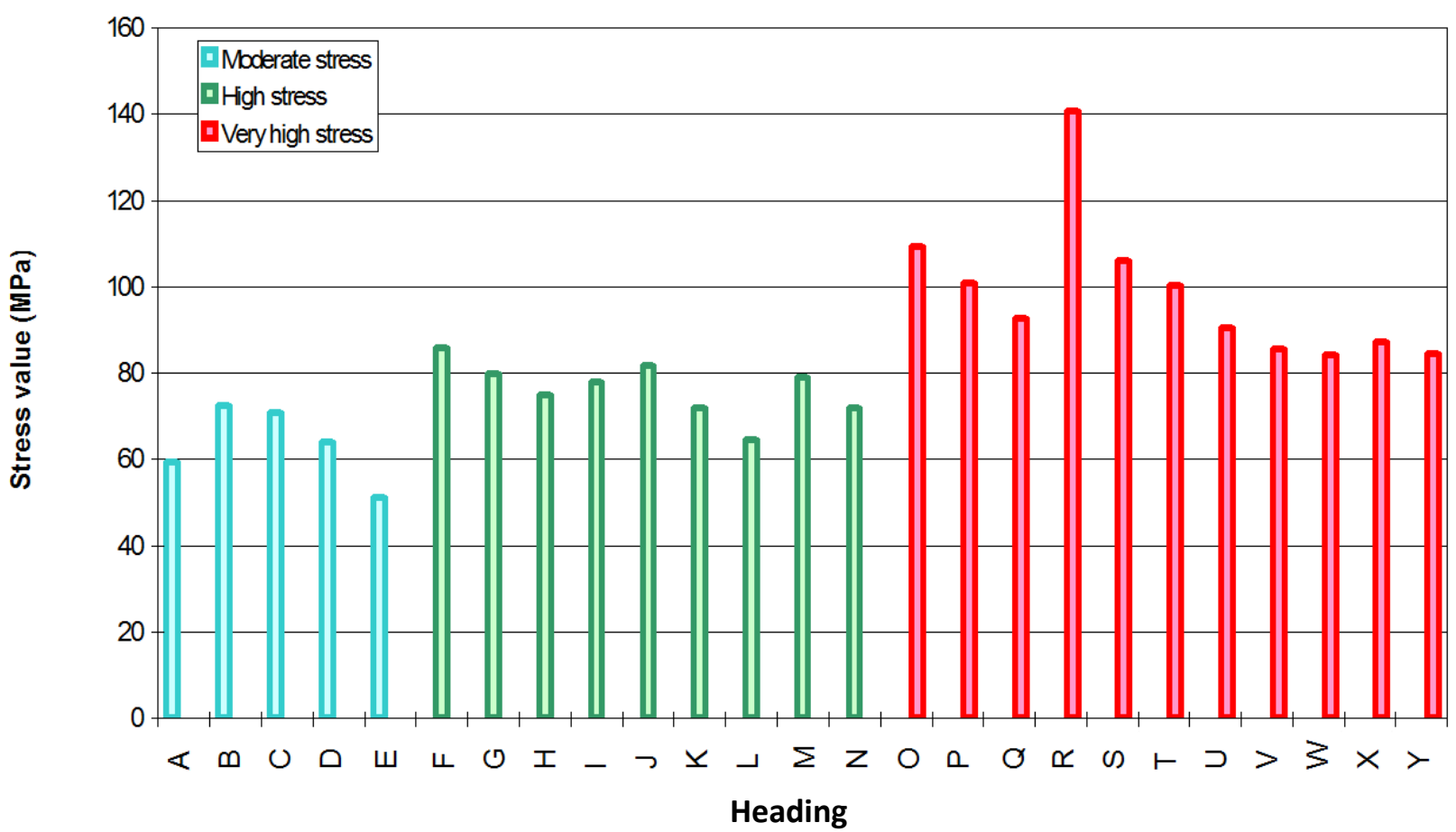

Figure 6 Underground observations plotted against $\sigma_{1}$-values

A fair distinction could be made between the categories with the $\sigma_{1}$ design criterion in Figure 6. 'Moderate stress' conditions prevail up to around $70 \mathrm{MPa}$, 'high stress' conditions from 70 to $85 \mathrm{MPa}$, and 'very high stress' conditions thereafter. Far-field $\sigma_{1}$ stresses of up to $110 \mathrm{MPa}$ were successfully accommodated and thus within site experience. The $140 \mathrm{MPa}$ case was identified as an artificial result and discounted.

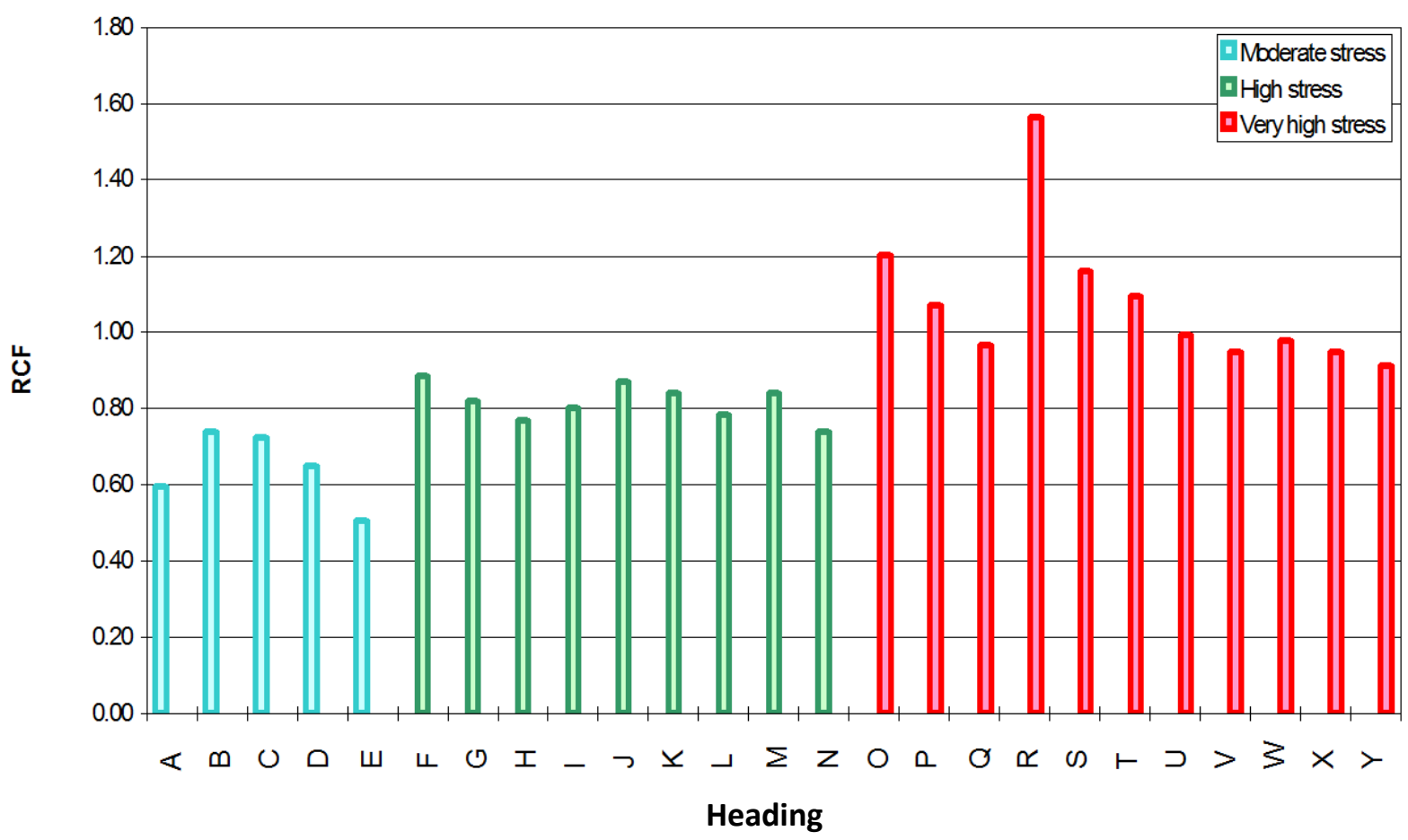

Figure 7 Underground observations plotted against RCF-values

A good distinction could be made between the categories with the RCF design criterion in Figure 7. 'Moderate stress' conditions prevail up to around a RCF-value of 0.75 , 'high stress' conditions from 0.75 to 
0.85 , and 'very high stress' conditions thereafter. RCF-values up to 1.2 were successfully accommodated and thus within site experience. The RCF-value of 1.55 was identified as an artificial result and discounted.

In this example, the RCF design criteria provided a better correlation with observed conditions, and used successfully for predictions and support design thereafter. The next case study shows how results from far-field design criteria can be visualised and effectively communicated to the Mine Planning Department.

\subsection{Example 2: far-field capital development standoff distance}

Presenting stress results as two-dimensional contours are common, but provide limited information about the general stress condition at the area of interest. Three-dimensional contours (iso-surfaces) provide the stress distribution within the rock mass as illustrated by Figure 8 . These iso-surfaces can be exported as DXF-files and used as design boundaries to guide the Mine Planning Department.

The iso-surface in Figure 8 represents the $80 \mathrm{MPa} \sigma_{1}$ far-field stress after extraction of the stopes, but the development was not included in the numerical model. Placing the development in the image with the stress iso-surface allows for quick assessments of the development placement in relation to high stress conditions.

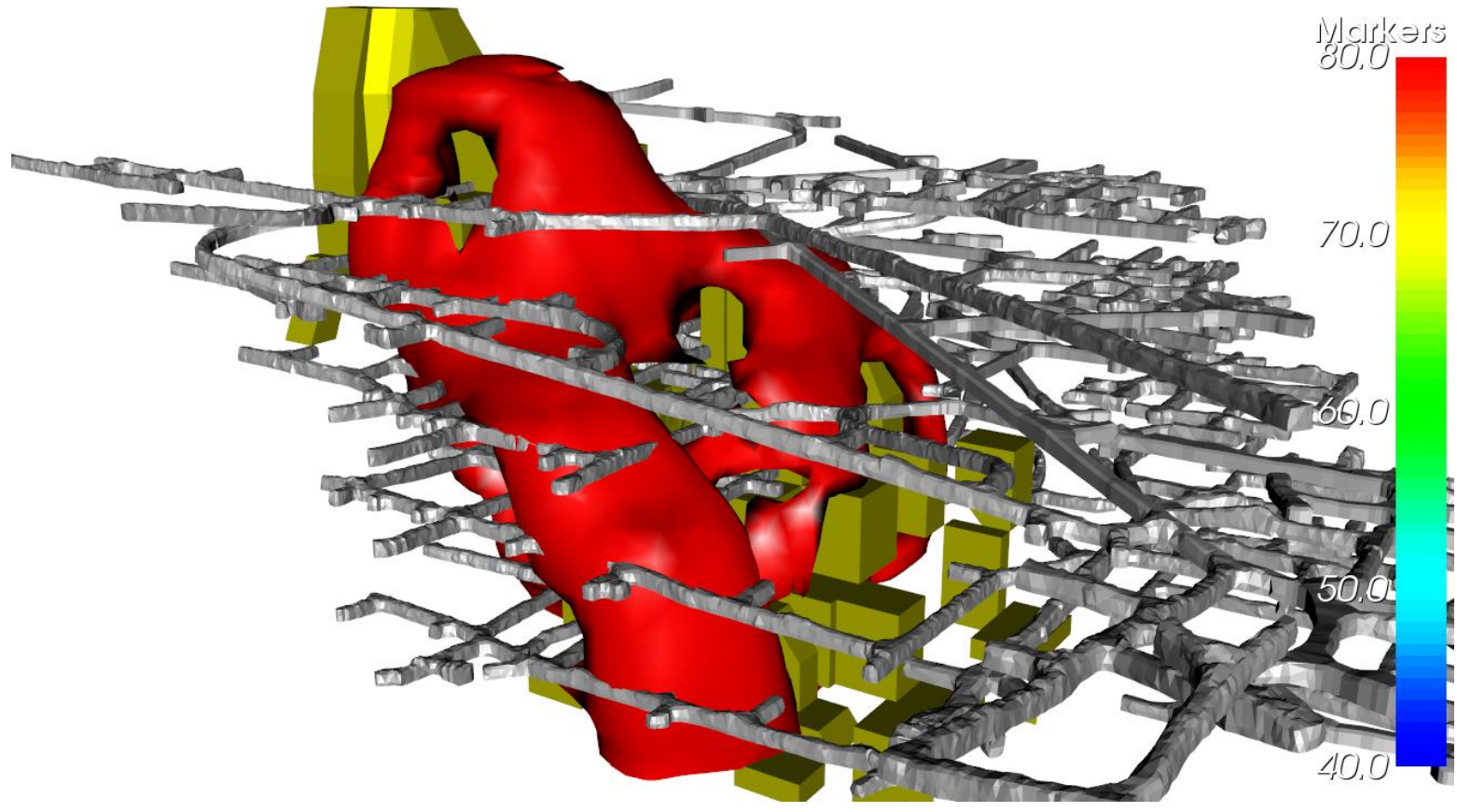

Figure 8 Screenshots of the far-field stress iso-surface calculated without the development in the numerical model. The screenshots were generated with GEM4D (BasRock Software for Geotechs 2015)

In addition, the iso-surface could be used as a guidance tool for planning engineers where geotechnical input is only required when the capital development intersects the boundary. This allows geotechnical stress modelling results to be incorporated in the mine design process. This method is not reserved for assessing existing development only, but can be used proactively in early mine design stages, enabling engineers to determine the balance between orebody stand-off distance and additional ground support requirements. This information can then also be built into life-of-mine cost models and budgets.

This visualisation method could be used to represent most design criteria, but is most often applied to the far-field stress and RCF-values. The benefit of this method is that many potential development locations can be evaluated with the same numerical modelling result. As shown in following sections, this visualisation technique can also be combined with other visualisation techniques for additional insights. 


\subsection{Example 3: heat-mapping of triangulations}

In underground mines, the majority of ground response observations are made in the access development. The easiest way to correlate the stress results with underground observations is to display both in the same image. Figure 9 shows the $\sigma_{1}$ stresses mapped as colours to the development, as well as damage observations as rectangles on top of development. The correlation between the stress condition and stress observations in the development is obvious in this case.

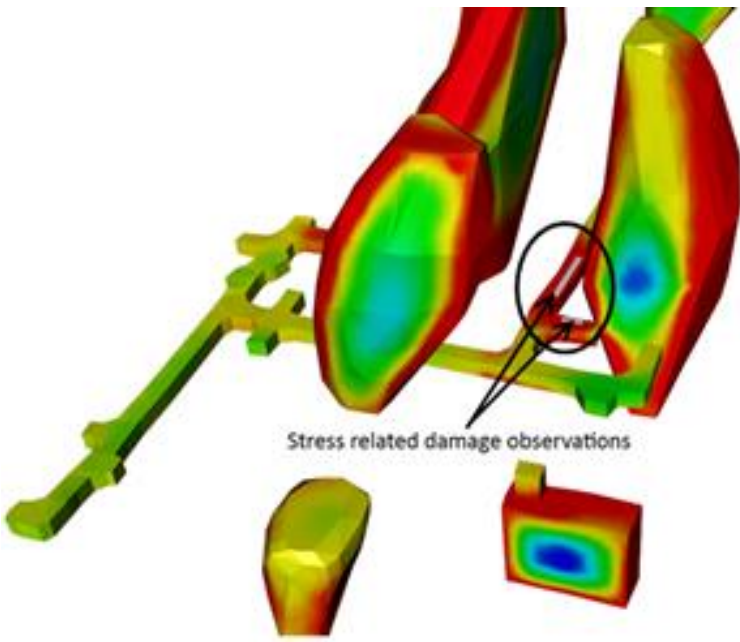

(a)

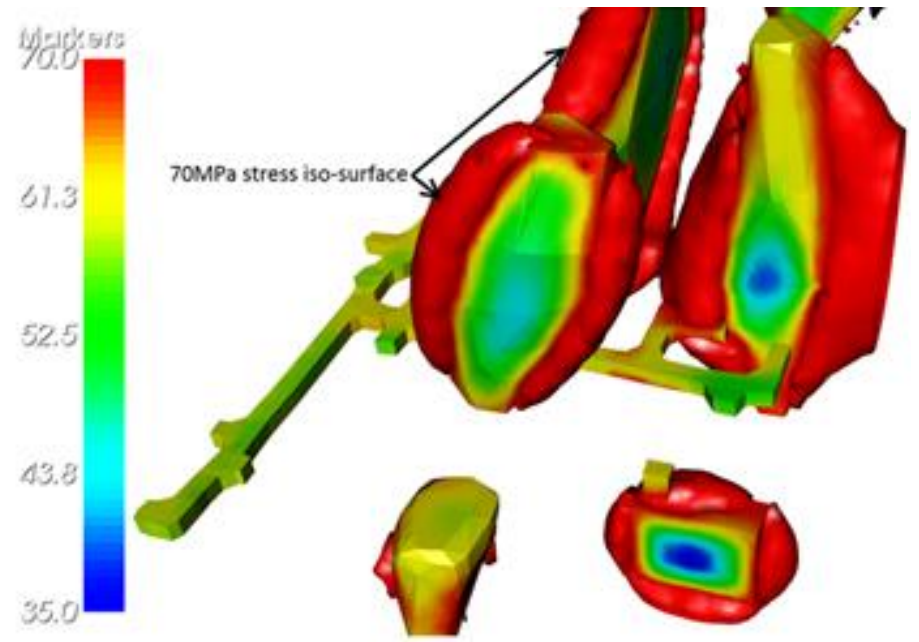

(b)

Figure 9 (a) meshes coloured on stress condition, with white rectangles at the observed damage locations; (b) an example of a combination of different visualisation techniques. The screenshots were generated with GEM4D (BasRock Software for Geotechs 2015)

\section{Conclusion}

Mining geotechnical engineers typically have incomplete information when making important decisions that could have substantial safety and production implications. Elastic numerical modelling results could provide useful inputs to the understanding of rock mass behaviour when design criteria are established. Care must be taken to select design criteria that are appropriate for the type of analysis required; for example, do not use RCF for near-field analysis.

The available visualisation options in modelling packages are limited, but modern visualisation tools are freely available and could assist to provide guidance to planning engineers in a manner that suits their design tools. Further, correlating observations with specific stress conditions are much simplified when the stresses are represented as iso-surfaces, or the excavation meshes coloured on the rock mass stresses in the vicinity.

\section{Acknowledgement}

The authors gratefully acknowledge the permission given by Newmont Asia Pacific and Newmont Tanami Operations, in particular, to publish this paper. Support from the rest of the site geotechnical team, particularly Hendra Arbi, Nathan Dalton and Gaudence Lijaji, is highly appreciated.

\section{References}

BasRock Software for Geotechs 2014, viewed 10 July 2015, http://www.basrock.com BasRock Software for Geotechs 2015, viewed 10 July 2015, http://www.basrock.net Louchnikov, V 2011, 'Simple calibration of the extension strain criterion for its use in numerical modelling', in Y Potvin (ed.) Proceedings of the Fourth International Seminar on Strategic versus Tactical Approaches in Mining, Australian Centre for Geomechanics, Perth, pp. 85-96. 
Ozbay, MU, Ryder, JA \& Jager, AJ 1995, 'The design of pillar systems as practiced in shallow hard-rock tabular mines in South Africa', Journal of the South African Institute of Mining and Metallurgy, pp. 7-18.

Sandy, MP, Sharrock, G, Albrecht, J \& Vakili, A 2010, 'Managing the transition from low stress to high stress conditions', Proceedings of the Second Australasian Ground Control in Mining Conference, The Australasian Institute of Mining and Metallurgy, Melbourne.

Stacey, TR 1981, 'A simple extension strain criterion for fracture of brittle rock', International Journal of Rock Mechanics and Mining Sciences \& Geomechanics Abstracts, vol. 18, no. 6, pp. 469-474.

Wiles, T 2004, Numerical Modelling Map3D course notes, Map3D International Ltd, http://www.map3d.com

Wiles, T 2015, Map3D software, Map3D International Ltd, http://www.map3d.com 
